\title{
On the Utility of E-Learning in Statistics
}

\author{
Wolfgang Härdle* \\ Sigbert Klinke* \\ Uwe Ziegenhagen*
}

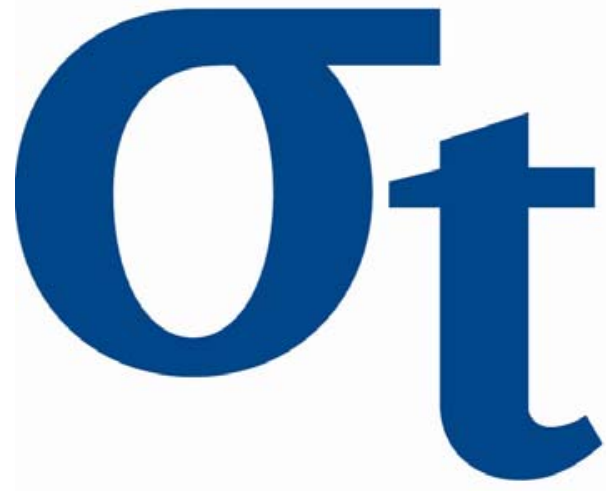

)

$\nabla$

$(0$

* Humboldt-Universität zu Berlin, Germany

This research was supported by the Deutsche Forschungsgemeinschaft through the SFB 649 "Economic Risk". 


\title{
On the Utility of E-Learning in Statistics*
}

\author{
Wolfgang Härdle ${ }^{1,2}$, Sigbert Klinke ${ }^{1}$ and Uwe Ziegenhagen ${ }^{1,2}$ \\ 1) Institute of Statistics and Econometrics (ISE) \\ 2) Center for Applied Statistics and Economics \\ School of Business and Economics \\ Humboldt-Universität zu Berlin
}

\begin{abstract}
Students of introductory courses consider statistics as particularly difficult, as the understanding of the underlying concepts may require more time and energy than for other disciplines. For decades statisticians have tried to enhance understanding with the help of technical solutions such as animation, video or interactive tools. However it is not clear if the added value generated by these e-learning tools justifies the work invested. In this paper the experience with various e-learning solutions in terms of utility and the impact on teaching is discussed.
\end{abstract}

AMS Classification: $97 \mathrm{U} 50$

JEL Classification I21, C19

\section{Introduction}

Before technical details are discussed it is necessary to clarify the vocabulary. E-learning describes all kinds of learning, where digital media are used for the presentation and transmission of learning materials and/or to support inter-human communication. In general e-learning tools can be grouped into:

- video conferencing and tele teaching systems

- simulations with or without user interaction

- learning (content) management tools

- content catalogues and podcasting

${ }^{*}$ This research was supported by the Deutsche Forschungsgemeinschaft through the SFB 649 "Economic Risk". 
- web and computerbased training applications

In the context of this paper the term e-learning refers mainly to the last category of this list, to web and computerbased training applications.

The projects proposed by Nolan and Lang (2008) and Darius et al. (2008) also fall into this category as they offer two different technical solutions to improve the understanding of statistics by students. Nolan and Lang (2008) propose a system for interactive and dynamic documents which allows students to follow the complex decision making process of a statistical analyst. As an example they take the classification of emails into spam and ham using different dialogues for, e.g. data loading, derivation of classification variables and statistical classification \& prediction.

Darius et al. (2008) present a set of Java applets to assist student understanding of experimental design. For two common situations in experimental design, the optimisation of an industrial process and a greenhouse experiment to find the optimal dose of fertilizer, they have developed interactive applets to provide their students with a test-bed for experimental design studies.

In the last few decades a plethora of interactive tools have been developed that aimed at helping students to receive a better understanding of statistics and to develop "statistical thinking". Some prominent commercial examples are Fathom (Keypress, 2007) or Visual Statistics (McGraw-Hill, 2001). Common internet search engines deliver more than one million hits for the search term "statistics applet".

The availability of web based content and pro-active statistics teaching tools however prompts, at least, the following two important questions:

1. Have students improved their statistics knowledge by using e-learning tools?

2. What impact do e-learning tools have on our teaching?

Since the results attained by students of statistics have not improved significantly, despite massive increases in the use of e-learning tool (at least in our experience), we are entitled to question the effectiveness of e-learning in statistics.

\subsection{Students vs. Statistics}

The reason that students encounter difficulties in statistics are complex and can, to a large part, be assigned to the students themselves and their lecturers. The PISA study revealed that the mathematical ability of German school students is significantly lower than the average of all OECD countries; in mathematics and natural sciences Germany was ranked 20 th out of 32 , in reading it was ranked even lower at place 21 .

These results, which reflect the high school performance, consequently also affect 
the ability of university students. An even more dramatic scenario has recently been discovered at the Johannes Kepler University Linz, Austria: Some of the original PISA exercises were given to students on the statistics course to check their basic mathematical knowledge, with questions such as "How much is $30 \%$ of $70 \%$ percent?". As Duller (2004, 2007a b) reported, the results were highly unsatisfactory and have even deteriorated since. The authors have the same impression. In fact exam grades have not improved although the standard of exams has been lowered over the last ten years.

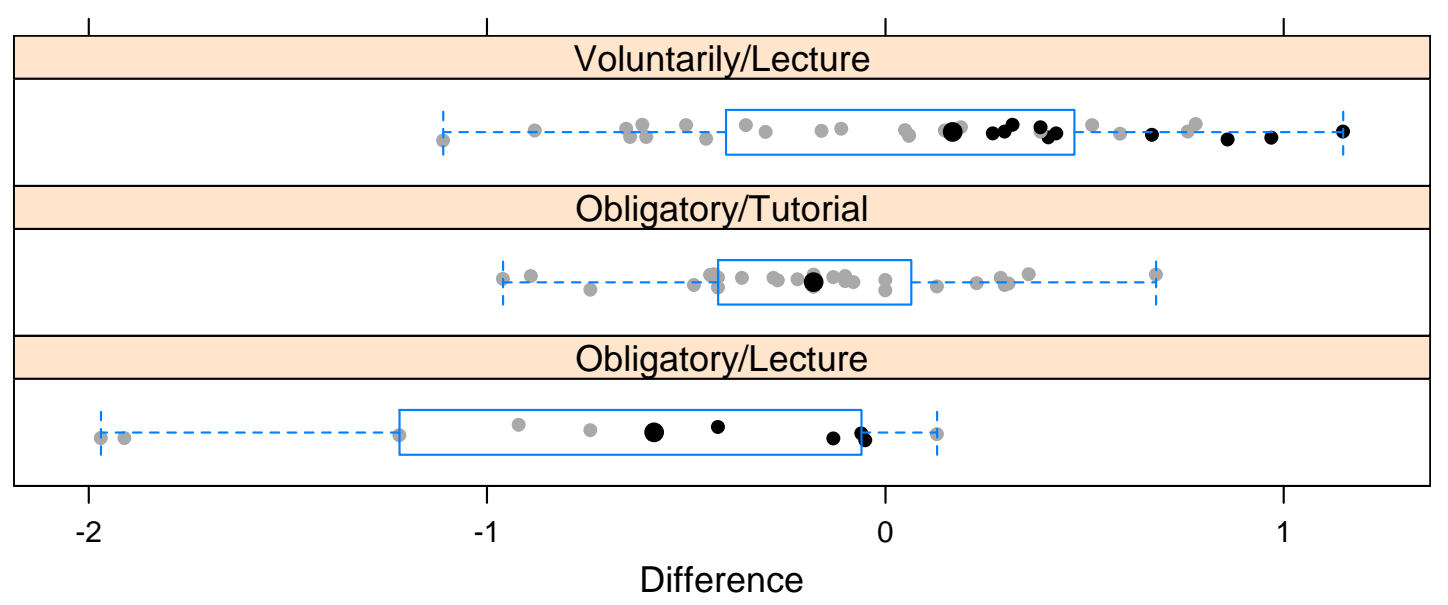

Figure 1: Difference of mean answers for statistics courses and mean of all courses (centred to 0) to the question "General impression of the course/course expectation fulfilled" ( $1=$ fully to $5=$ not at all) from winter term 1999/2000 until summer term 2006 by course attributes (obligatory/voluntarily visit and lecture/tutorial). The small black dots represent one particular teacher.

The comparatively low competence in mathematics may also provide hints for the evaluation of the statistics courses at the School of Business and Economics at HumboldtUniversität, Berlin. For more than ten years now students have evaluated courses and lecturers. Figure 1 shows (at the bottom) the difference between the average answer to the questions "General impression of course/course expectation fulfilled" for the compulsory course in statistics (comparable to STAT101 courses in the United States), the voluntary exercises (middle) and all other voluntary courses from the authors institute for the Winter Term 1999/2000 until the Summer Term 2006. As the average of all courses from the faculty was centred to 0 , the graphs indicate that even a specifically good teacher (evaluated above average from the advanced students) does not fulfill all expectations for the introductory courses.

The overall average of the statistics courses is around -0.12 , verbal comments from the students name three problems in the compulsory basic courses as well as in the voluntary advanced courses in statistics, these are: 
1. too formal, too much mathematics

2. too fast, too much content in the curriculum

3. not enough examples

The first point of criticism adresses the difficult problem of balancing between mathematical formalism and looseness. In the authors' opinion there will always be students who complain about the level of formalism. A significant part of statistics requires solid and basic mathematics, therefore there must be a minimum level of formalism and mathematical rigour. However we agree with Nolan and Lang (2008), that visualisation, simulation and computing provide alternative lenses through which to view statistical problems.

The covered topics in the curriculum are associated with the way courses are taught. In most universities there is little need to write on a board as there is a prepared set of digital slides either in Powerpoint or Adobe PDF format. The slide set for the two-term introductory course in statistics at the School of Business and Economics contains, for example, nearly 700 slides covering ten topics. The advantage of slides is obvious. One can easily add links to data sources or include low level dynamic content.

Experience and feedback from students together with the aim of proliferating existing content drove the development of electronic teaching material. By distributing course material in a convenient (electronic) form students have a chance to concentrate on lectures rather than copying the content of slides. By providing examples that would be too time-consuming or complex for the lecture it has been tried to support the students' understanding. And finally various web based learning environments have been developed that will be described in the next section.

The last point of criticism by students is the lack of examples, a point we partly agree with as it can be very difficult to develop excellent examples especially for introductory courses. Our experience is that if one global example is used throughout the lecture to explain various concepts some students complain about the "single boring" example, if on the other hand, we use several examples the students may fail to see the associations between the different topics in the course.

\subsection{Online Learning Tools}

Like Nolan and Lang (2008) and Darius et al. (2008) we have tried to supplement our class notes with various e-learning tools. These in detail:

- $\mathrm{MM}^{*}$ Stat, an interactive browser-based tool for statistics

- Electronic books, result of a cooperation with Springer

- Questions \& Answers, a web based exam preparation tool

- Microsoft Excel, to provide spread-sheet based examples 
- TeachWiki, a collaborative environment on Wiki basis

$\mathrm{MM}^{*}$ Stat (Müller et al., 2000) is aimed at supplementing the traditional lectures by creating a framework to repeat and practise the content of lectures. The system is available in various languages such as English, German, French, Spanish and many more. Using a HTML-based tab structure which was generated from $\mathrm{HT}_{\mathrm{E}} \mathrm{X}$ using the MD*Book system (Klinke and Lehmann, 2003) with "lecture" tabs providing definitions, formulas and graphics and various example tabs the student can follow the lecture step by step. Since the different tabs are connected with links the student may jump between the different lectures and the glossary, which provides brief definitions for each term used.

To provide interactivity two different approaches have been used. There are not only multiple choice questions at the end of each chapter which are evaluated via Javascript, but also interactive examples based on a client/server solution featuring the XploRe Quantlet Server (XQS) and the XploRe Quantlet Client (Lehmann et al., 2005) which visualise, for example, parameter changes for statistical distributions and tests. The system is available for various languages, Figure 2 depicts a lecture tab in Arabic and English, with links to the examples in the bottom right-hand corner.

In order to generate additional value for printed media, in terms of allowing the reader to interactively modify and run the examples from a textbook, the XQS technology used for $\mathrm{MM}^{*}$ Stat has been applied to books, which have been designed for 2nd year and above students. Each book (see http://www.xplore-stat.de/ebooks/ebooks.html), its HTML version and the corresponding set of slides contain references to web pages on a webserver. These HTML pages show the XploRe source code and allow the examples to be run in the Java Quantlet Client applet; experienced users may also modify the source code. Figure 3 shows an example taken from the book Applied Multivariate Analysis Härdle and Simar (2007).

The Questions \& Answers (Q\&A) system, Klinke (2004), was designed specifically for students who want to practice multiple choice question that had played a significant role in the undergraduate exams. Despite the different books the students can use for exam preparation certain, very common errors can be seen. Within the Q \& A project the errors are specified on the basis of evaluated exams, for each exercise the different results are computed if a student makes a particular error. When the student then clicks one of the wrong answers the lecturer can see exactly where the source of the error is and explain the topic again in the next lecture. Figure 4 shows an example questions 


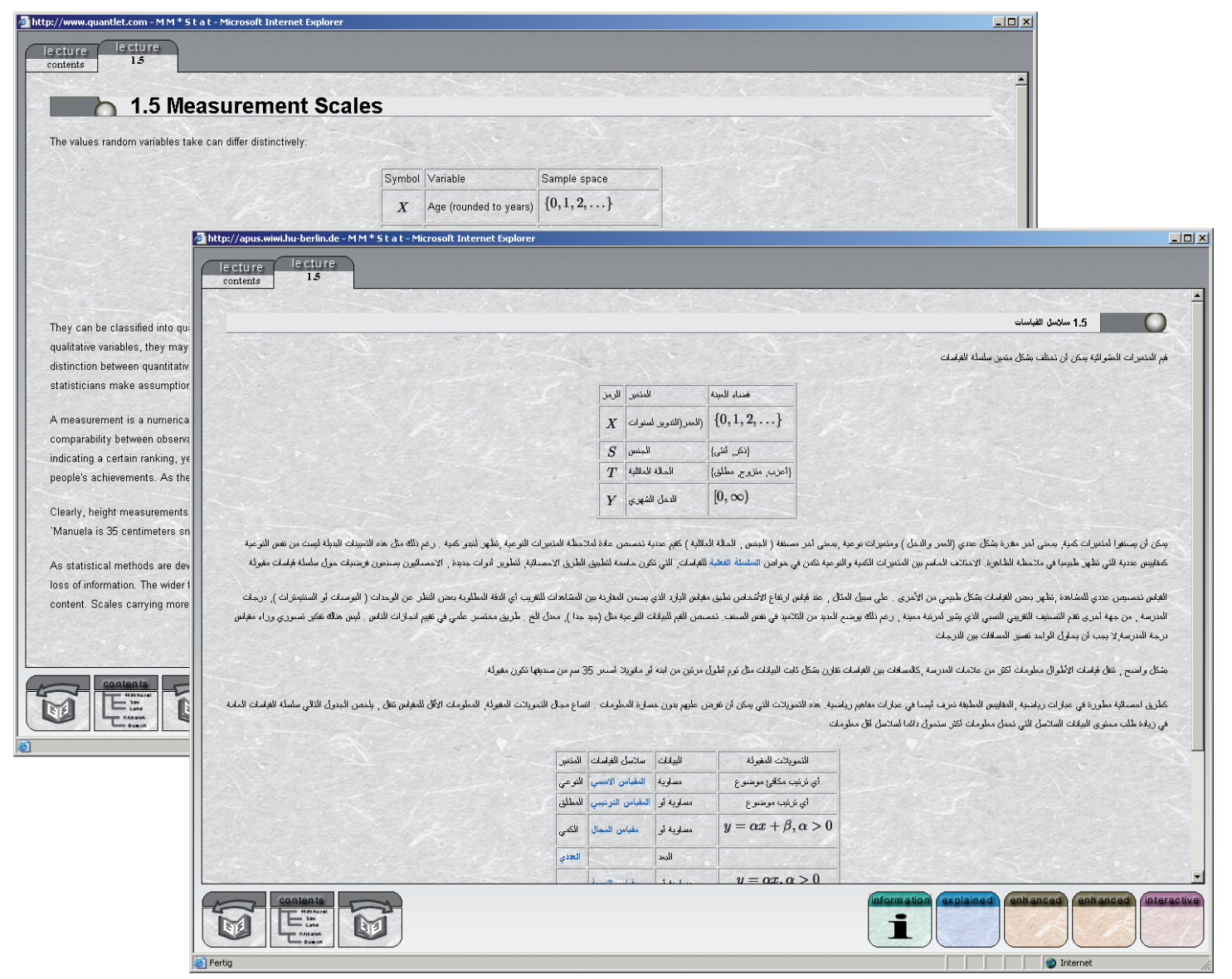

Figure 2: Screenshot of $\mathrm{MM}^{*}$ Stat, English and Arab version

from Q \& A: Given some information about the situation the student has to click one or more boxes; these are evaluated immediately. However, we have found that instead of thinking carefully about a solution, a significant proportion of students just click until they receive a correct answer.

The TeachWiki project is another web based project but with a strong focus on collaborative work. Usually seminar theses remain in the basement, with TeachWiki we allow the students theses to be published to a broader audience. The system is based on the MediaWiki technology of Wikipedia and enhanced to integrate LaTeX syntax for formulas and a plug-in to integrate $\mathrm{R}$ code. The idea is also to provide the students with a platform where they can easily work jointly on a seminar thesis.

Besides these proprietary tools standard spreadsheet software (Microsoft Excel) is used in our courses. Excel has the advantage of being available on nearly every computer and the majority of students knows at least the basic commands to work with the software. In our institute Excel spreadsheets are mainly used for the education of undergraduate 


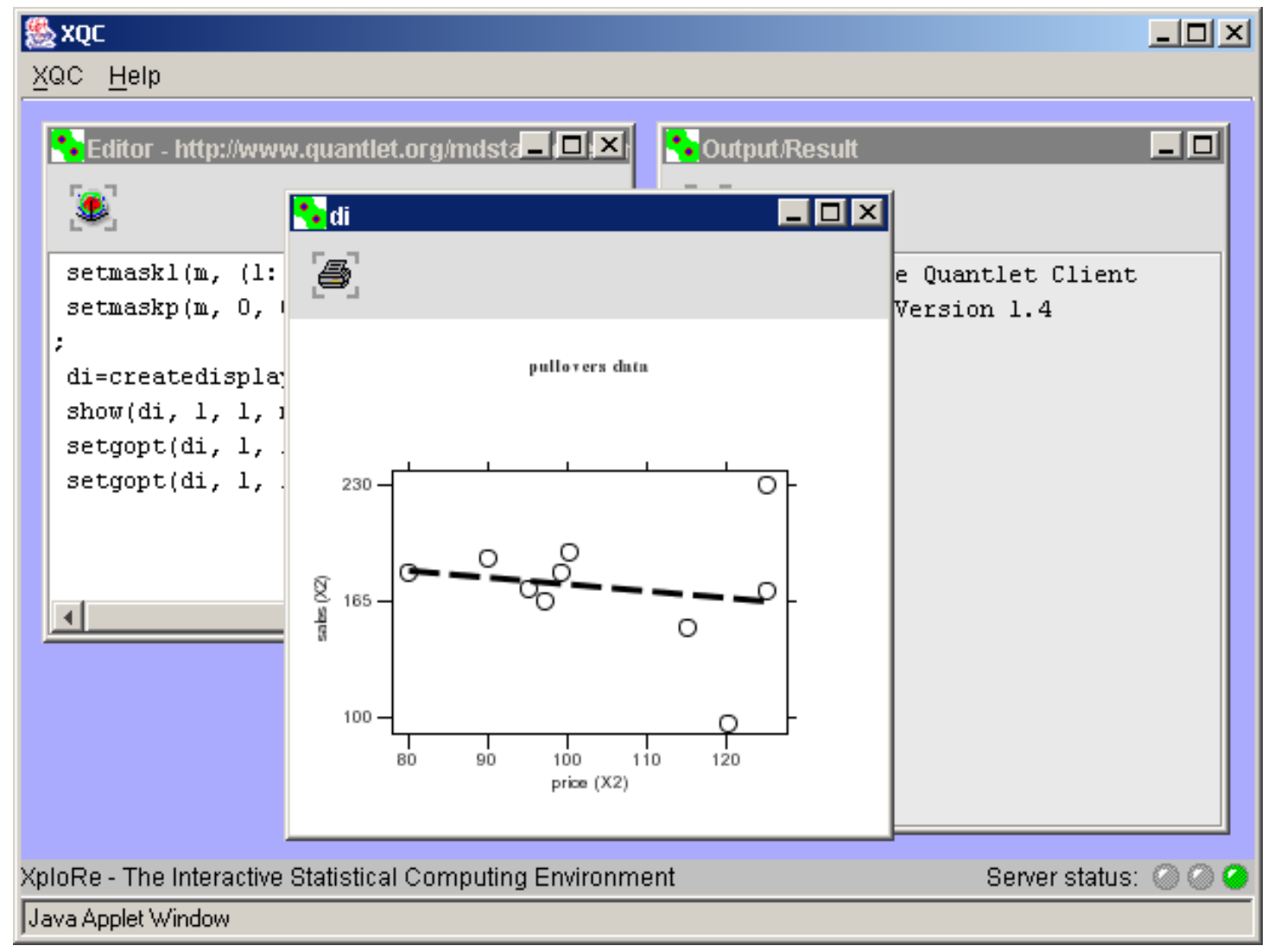

Figure 3: Screenshot of an interactive example from the 'Applied Multivariate Statistics' book

students, e.g. to visualise the Central Limit Theorem or the parameter changes of distribution functions. The built-in functions are easily accessible, without having to know a high-level programming language such as Java or $\mathrm{C}++$ formulas may be edited or graphical user interface components such as sliders, radiobuttons and pull-down menus can be used. Even real-time sound generation can be visualised with Excel (Neuwirth, 2007).

Figure 5 displays a screenshot of a spreadsheet to visualize eight different probability density functions where the parameters can be modified via sliders, Figure 6 shows a visualisation of the basic algorithm for kernel density estimation.

\subsection{Impact on Teaching}

As mentioned above the style and methods of teaching have changed from a board centred approach to electronic slides and beamer presentations. This solution may have 


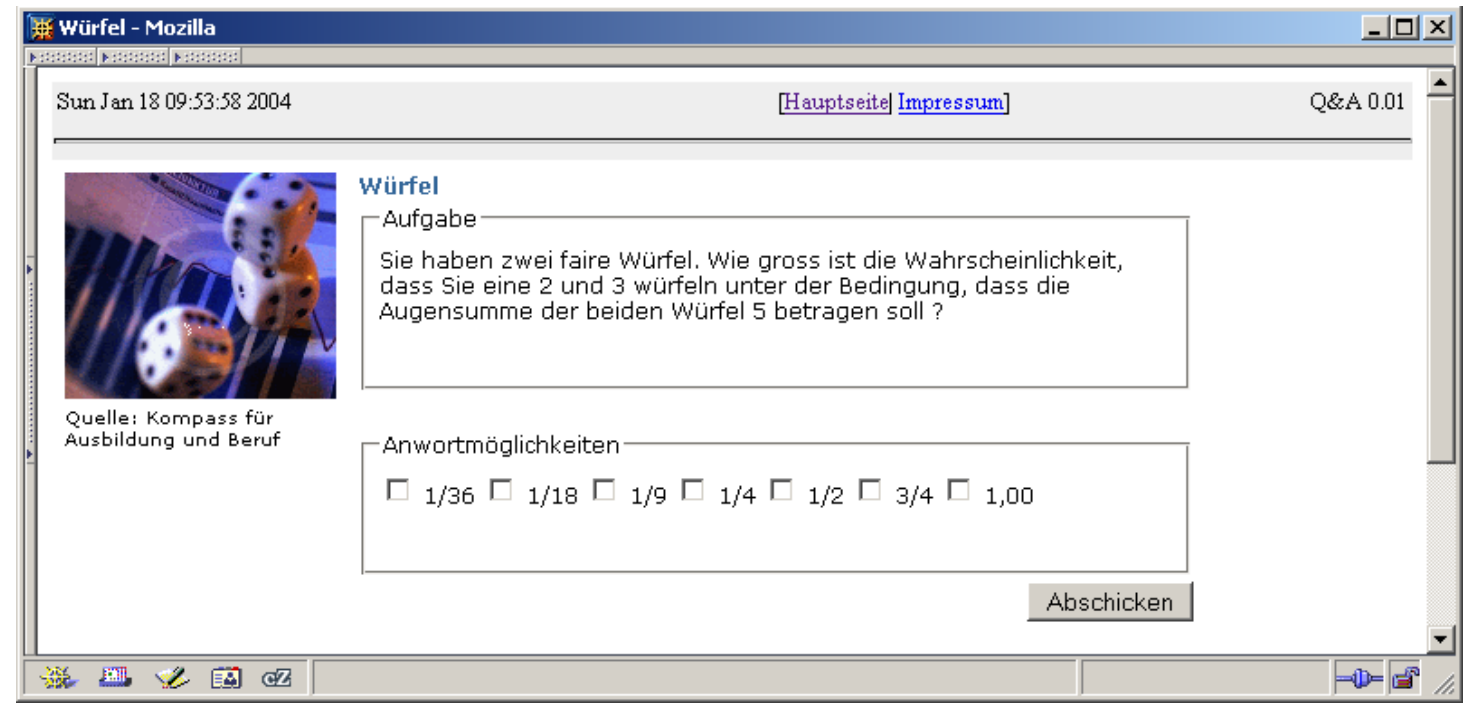

Figure 4: An exercise from Q\&A: "Given you throw two fair dices what is the probability of throwing a 2 and a 3 given the sum of boths throws was 5 ?"

disadvantages not only for the student (the curriculum is much larger), but also for the lecturer. In the same way as that it is generally not possible to do parallel beamer presentations and use a board - due to for example light conditions or the available projection space, the lecturer cannot leave the media and, for example, quickly add a drawing.

In general different problems present themselves, which may prevent or interfere the successful use of e-Learning tools:

Technical problems: e-Learning projects usually have to commit themselves to a certain platform. For many - especially smaller - opensource projects there is no guarantee that the software platform will be supported in a few years or that future versions will be compatible. Even commercial software products frequently disappear from the market, so the decision to use a certain platform must be well thought through. As the funding for a bigger project is often limited to a certain time window, one has to ask about the project maintenance after the funding has ceased.

Administrative overhead: The truth is simple: Excellent projects require excellent ideas and funding and usually provide more work than a single person can handle. The administrative work (security, access control) which has nothing to do with the original goal of teaching statistics often exceeds the usefulness of a supporting tool and rather becomes a burden.

Specialisation: E-learning tools are often developed by small teams for a special concept only. Since the documentation and publication of the source codes usually receives a comparatively low weight, it may be easier for other projects to implement their 


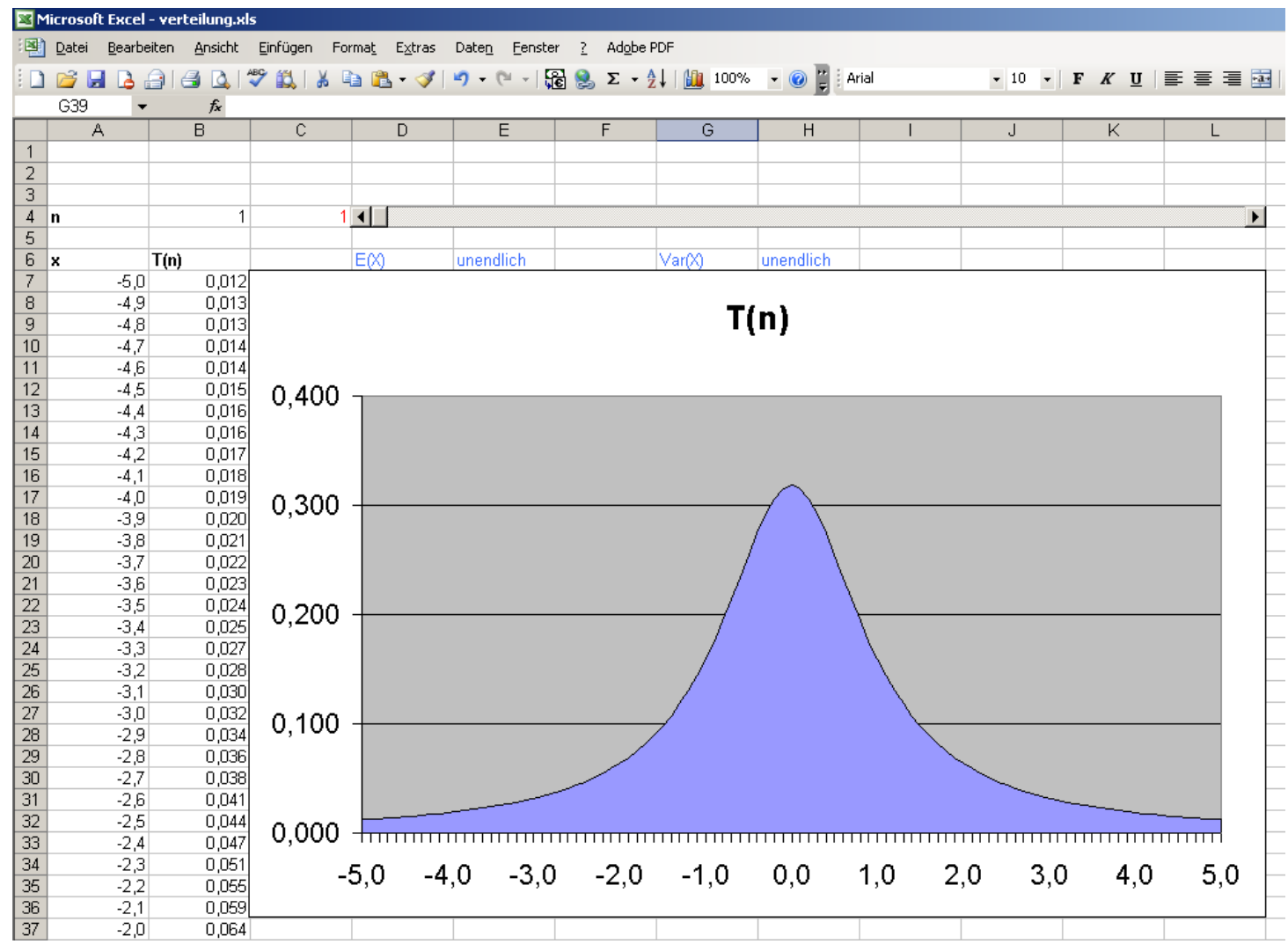

Figure 5: Visualisation of parameter changes with Excel

own solutions. A Google search for "Java Applet Histogram" returns nearly 200000 hits. Even if this number overestimates the true number of histogram applets there are still thousands of applets with more or less the same functionality.

Availability: The setup and handling of e-learning tools can be difficult especially if they require the installation of server software such as Apache, PHP or Java. Microsoft Excel on the contrary can be considered as one of the software packages that every student has access to; and although it may not provide enough precision or speed to do deep data analysis, its features are sufficient for interactive visualisation of e.g. parameter changes of distributions. This platform suits students that belong to the increasing number of "button-pushers". Only a very small fraction prefers to use command-driven interfaces. In our experience "just clicking a button" also lowers the students willingness to question the appropriateness of an algorithm or method in certain situations. In this sense we must complement the recommendation of Nolan and Lang (2008) of "simplifying how we do do what we do, not what we do" by "and explain why we do".

Evaluation: We are not aware of any resonable study in the area of statistics where it is proven that the use of interactive tools improves student understanding. Most 


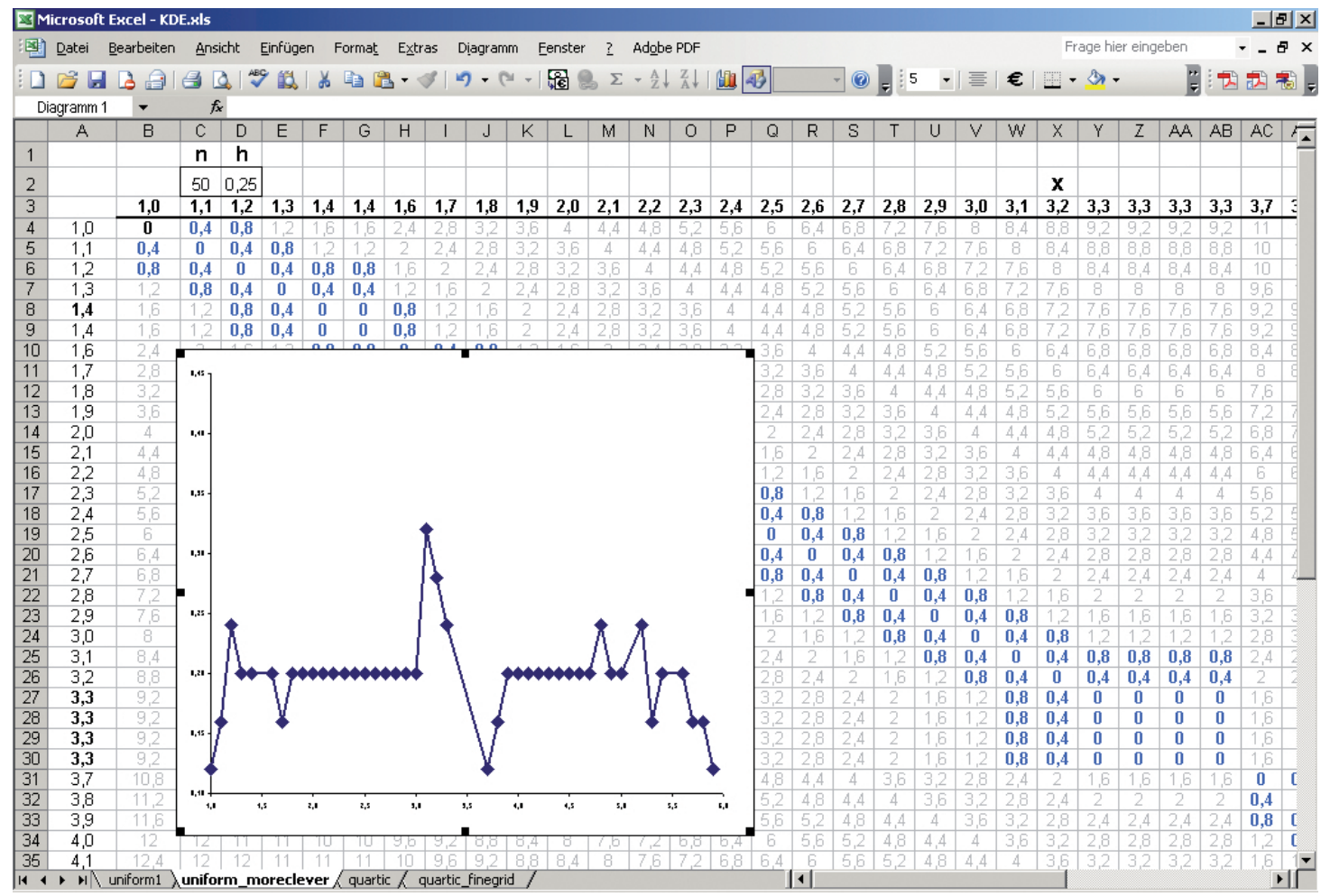

Figure 6: Visualisation of Kernel Density Estimation with Excel

projects, for example, report the number of accesses on project web pages etc., but no hard proof in terms of increased student grades in an experiment is given.

Darius et al. (2008) present a questionnaire they had asked their students to complete but cannot now generate a numerical analysis since the experimental design software has changed over time.

In the introductory statistics course at the School of Business and Economics students receive a $\mathrm{MM}^{*}$ Stat $\mathrm{CD}-\mathrm{ROM}$ and although the students' comments are very positive an evaluation (Brandes, 2004) showed no significant improvement in the grades. Personal feedback from students has shown that the CD-ROM was used more as a replacement for textbooks than as an interactive e-learning tool.

Didactic concept: Didactic concepts are ofter not discussed or questions concerning technical implementations receive a much heavier importance in the development process. Most developers of e-learning projects are not educated in didactics but are mathematicians, statisticians or programmers.

All the above points boil down to one question: Is the possible positive effect an elearning tool may have on students understanding worth the effort the teacher needs to invest in it? 
We have considered the utility of e-teaching statistics for the particular field of web and computerbased training applications and reviewed ten years worth of large-scale integrated electronic media elements in different areas of statistics education. The electronic media ranged from relatively simple Excel spreadsheets to integrated learning enviroments on the basis of HTML and Java. The aim of these implementations was to achieve improvements in the understanding of statistical concepts with the ultimate goal of better exam grades. We have found that the utility is marginal in comparison with the effort invested.

We believe that e-learning is required in modern statistics education but we do not share a too optimistic view that it will also deepen the knowledge of students in statistics. We rather believe that e-learning can be a valuable for a certain proportion of students.

\section{References}

Ulrike Brandes. Statistische Bewertung und Analyse der Klausurergebnisse Statistik (Grundstudium). Diploma thesis, 2004. URL http://edoc.hu-berlin.de/ docviews/abstract $\cdot$ php?lang=ger\&id=26854.

Paul L. Darius, Kenneth M. Portier, and Eddie Schrevens. Data collection skills: Challenges for teaching and training. International Statistical Review, 2008.

Christine Duller. A kind of PISA-survey at university. In J. Antoch, editor, Proceedings in Computational Statistics - 16th Symposium held in Prague, Physika Verlag, Heidelberg, pages 975-980, 2004.

Christine Duller. Doing statistics versus understanding statistics. In DAGStat - Statistics under one Umbrella, page 88, 2007a.

Christine Duller. Do you speak statistics? In Proceedings of the ISE, 2007b.

Wolfgang Härdle and Leopold Simar. Applied Multivariate Statistics. Springer, Heidelberg, 2 edition, 2007.

Keypress. Fathom 2. Software, 2007. URL http://www.keypress.com/x5656.xml.

Sigbert Klinke. Q\&A - variable multiple choice exercises with commented answers. In J. Antoch, editor, Proceedings in Computational Statistics - 16th Symposium held in Prague, Physika Verlag, Heidelberg, pages 1299-1304, 2004.

Sigbert Klinke and Heiko Lehmann. MD*Book and XQC/XQS - an architecture for reproducible research. SFB 373 Discussion Paper, 2003.

Heiko Lehmann, Szymon Borak, and Wolfgang Härdle. Statistical Tools for Finance and Insurance, chapter Working with the XQC. 2005. 
McGraw-Hill. Visual Statistics. Software, 2001. URL http://www . mhhe.com/business/ opsci/doane/home.htm.

Marlene Müller, Bernd Rönz, and Uwe Ziegenhagen. The multimedia project MM*STAT for teaching statistics. In Jelke Bethlehem and Peter van der Heijden, editors, Proceedings in Computational Statistics - 14th Symposium held in Utrecht, pages 409-415, 2000. URL http://www.quantlet.com/mdstat/mmstat.html.

E. Neuwirth. Spreadsheets in education, 2007. URL http://sunsite.univie.ac.at/ Spreadsite/.

Deborah Nolan and Duncan Temple Lang. Dynamic, interactive documents for teaching statistical practise. International Statistical Review, 2008. 


\section{SFB 649 Discussion Paper Series 2007}

For a complete list of Discussion Papers published by the SFB 649, please visit http://sfb649.wiwi.hu-berlin.de.

001 "Trade Liberalisation, Process and Product Innovation, and Relative Skill Demand" by Sebastian Braun, January 2007.

002 "Robust Risk Management. Accounting for Nonstationarity and Heavy Tails" by Ying Chen and Vladimir Spokoiny, January 2007.

003 "Explaining Asset Prices with External Habits and Wage Rigidities in a DSGE Model." by Harald Uhlig, January 2007.

004 "Volatility and Causality in Asia Pacific Financial Markets" by Enzo Weber, January 2007.

005 "Quantile Sieve Estimates For Time Series" by Jürgen Franke, JeanPierre Stockis and Joseph Tadjuidje, February 2007.

006 "Real Origins of the Great Depression: Monopolistic Competition, Union Power, and the American Business Cycle in the 1920s" by Monique Ebell and Albrecht Ritschl, February 2007.

007 "Rules, Discretion or Reputation? Monetary Policies and the Efficiency of Financial Markets in Germany, 14th to 16th Centuries" by Oliver Volckart, February 2007.

008 "Sectoral Transformation, Turbulence, and Labour Market Dynamics in Germany" by Ronald Bachmann and Michael C. Burda, February 2007.

009 "Union Wage Compression in a Right-to-Manage Model" by Thorsten Vogel, February 2007.

010 "On $\sigma$-additive robust representation of convex risk measures for unbounded financial positions in the presence of uncertainty about the market model" by Volker Krätschmer, March 2007.

011 "Media Coverage and Macroeconomic Information Processing" by Alexandra Niessen, March 2007.

012 "Are Correlations Constant Over Time? Application of the CC-TRIG -test $^{-}$ to Return Series from Different Asset Classes." by Matthias Fischer, March 2007.

013 "Uncertain Paternity, Mating Market Failure, and the Institution of Marriage" by Dirk Bethmann and Michael Kvasnicka, March 2007.

014 "What Happened to the Transatlantic Capital Market Relations?" by Enzo Weber, March 2007.

015 "Who Leads Financial Markets?" by Enzo Weber, April 2007.

016 "Fiscal Policy Rules in Practice" by Andreas Thams, April 2007.

017 "Empirical Pricing Kernels and Investor Preferences" by Kai Detlefsen, Wolfgang Härdle and Rouslan Moro, April 2007.

018 "Simultaneous Causality in International Trade" by Enzo Weber, April 2007.

019 "Regional and Outward Economic Integration in South-East Asia" by Enzo Weber, April 2007.

020 "Computational Statistics and Data Visualization" by Antony Unwin, Chun-houh Chen and Wolfgang Härdle, April 2007.

021 "Ideology Without Ideologists" by Lydia Mechtenberg, April 2007.

022 "A Generalized ARFIMA Process with Markov-Switching Fractional Differencing Parameter" by Wen-Jen Tsay and Wolfgang Härdle, April 2007.

\section{SFB 649, Spandauer Straße 1, D-10178 Berlin} http:/ / sfb649.wiwi.hu-berlin.de

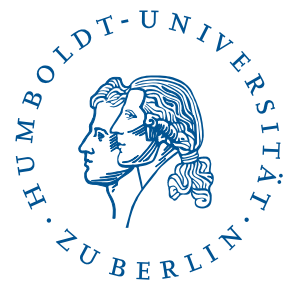


023 "Time Series Modelling with Semiparametric Factor Dynamics" by Szymon Borak, Wolfgang Härdle, Enno Mammen and Byeong U. Park, April 2007.

024 "From Animal Baits to Investors' Preference: Estimating and Demixing of the Weight Function in Semiparametric Models for Biased Samples" by Ya'acov Ritov and Wolfgang Härdle, May 2007.

025 "Statistics of Risk Aversion" by Enzo Giacomini and Wolfgang Härdle, May 2007.

026 "Robust Optimal Control for a Consumption-Investment Problem" by Alexander Schied, May 2007.

027 "Long Memory Persistence in the Factor of Implied Volatility Dynamics" by Wolfgang Härdle and Julius Mungo, May 2007.

028 "Macroeconomic Policy in a Heterogeneous Monetary Union" by Oliver Grimm and Stefan Ried, May 2007.

029 "Comparison of Panel Cointegration Tests" by Deniz Dilan Karaman Örsal, May 2007.

030 "Robust Maximization of Consumption with Logarithmic Utility" by Daniel Hernández-Hernández and Alexander Schied, May 2007.

031 "Using Wiki to Build an E-learning System in Statistics in Arabic Language" by Taleb Ahmad, Wolfgang Härdle and Sigbert Klinke, May 2007.

032 "Visualization of Competitive Market Structure by Means of Choice Data" by Werner Kunz, May 2007.

033 "Does International Outsourcing Depress Union Wages? by Sebastian Braun and Juliane Scheffel, May 2007.

034 "A Note on the Effect of Outsourcing on Union Wages" by Sebastian Braun and Juliane Scheffel, May 2007.

035 "Estimating Probabilities of Default With Support Vector Machines" by Wolfgang Härdle, Rouslan Moro and Dorothea Schäfer, June 2007.

036 "Yxilon - A Client/Server Based Statistical Environment" by Wolfgang Härdle, Sigbert Klinke and Uwe Ziegenhagen, June 2007.

037 "Calibrating CAT Bonds for Mexican Earthquakes" by Wolfgang Härdle and Brenda López Cabrera, June 2007.

038 "Economic Integration and the Foreign Exchange" by Enzo Weber, June 2007.

039 "Tracking Down the Business Cycle: A Dynamic Factor Model For Germany 1820-1913" by Samad Sarferaz and Martin Uebele, June 2007.

040 "Optimal Policy Under Model Uncertainty: A Structural-Bayesian Estimation Approach" by Alexander Kriwoluzky and Christian Stoltenberg, July 2007.

041 "QuantNet - A Database-Driven Online Repository of Scientific Information" by Anton Andriyashin and Wolfgang Härdle, July 2007.

042 "Exchange Rate Uncertainty and Trade Growth - A Comparison of Linear and Nonlinear (Forecasting) Models" by Helmut Herwartz and Henning Weber, July 2007.

043 "How do Rating Agencies Score in Predicting Firm Performance" by Gunter Löffler and Peter N. Posch, August 2007.

\section{SFB 649, Spandauer Straße 1, D-10178 Berlin} http:/ / sfb649.wiwi.hu-berlin.de

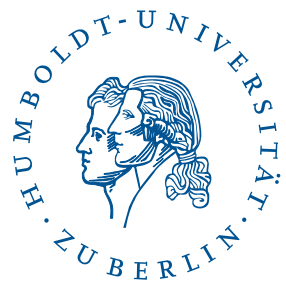


044 "Ein Vergleich des binären Logit-Modells mit künstlichen neuronalen Netzen zur Insolvenzprognose anhand relativer Bilanzkennzahlen" by Ronald Franken, August 2007.

045 "Promotion Tournaments and Individual Performance Pay" by Anja Schöttner and Veikko Thiele, August 2007.

046 "Estimation with the Nested Logit Model: Specifications and Software Particularities" by Nadja Silberhorn, Yasemin Boztuğ and Lutz Hildebrandt, August 2007.

047 "Risiken infolge von Technologie-Outsourcing?" by Michael Stephan, August 2007.

048 "Sensitivities for Bermudan Options by Regression Methods" by Denis Belomestny, Grigori Milstein and John Schoenmakers, August 2007.

049 "Occupational Choice and the Spirit of Capitalism" by Matthias Doepke and Fabrizio Zilibotti, August 2007.

050 "On the Utility of E-Learning in Statistics" by Wolfgang Härdle, Sigbert Klinke and Uwe Ziegenhagen, August 2007. 